ISBN 978-93-84468-83-5

International Conference on Issues in Business, Economics, Marketing and Mathematics

(IBEMM-16)

Singapore Dec. 5-6, 2016

\title{
Social Entrepreneurship and It's Role towards Poverty Reduction: A Comparative Study between Indonesia and Thailand Context
}

\author{
${ }^{1}$ Lieli Suharti, ${ }^{2}$ Roos Kities Andadari, ${ }^{3}$ Hani Sirine, and ${ }^{4}$ Soomboon Panyakom \\ (Lieli.suharti@staff.uksw.edu, Roos.kities@staff.uksw.edu, hani.sirine@staff.uksw.edu) \\ ${ }^{1,2,3}$ Faculty of Economics and Business, Satya Wacana Christian University, Indonesia \\ ${ }^{4}$ Payab University, Chiang Mai Thailand (spanyakom@gmail.com)
}

\begin{abstract}
Social Entrepreneurship (SE) is believed as one of the ideal solutions to reduce the number of unemployment and poverty. Some prior studies suggest that SE may leads to significant changes in the social, political, and economic contexts for poor and marginalized groups. This research aims to examine and analyze SE in Indonesia and Thailand context. The main purpose of the research is to find out whether local social enterprises can become drivers of poverty reduction in the region. More specific, the research questions of this study are: 1) How is SE evolved in the region?; 2) What are the internal and external factors that drive the raise of SE in the region?; and 3) How does SE benefit for local people and poverty reduction?.

The target population of this research involves SE in Indonesia and Thailand. The study design was a multiple case study. The study provides a comparative analysis of 6 cases of SE in each country.

The results showed there are differences with regard to the emergence and development of SE in Indonesia with $S E$ in Thailand. The study also found there are number of internal and external factors that pushed the raise of $S E$ in the region. Finally, the results also showed that the SE provides many benefits to local community, among others in the form of employment, increased prosperity and increased quality of life of the local people.
\end{abstract}

Keywords--- Social entrepreneurship, poverty reduction, comparative study, Thailand, Indonesia

\section{Introduction}

In the mid-to-late 2000, Social Entrepreneurship and Philanthropy have become significance to the public awareness in western countries and rapidly growing worldwide, particularly in Asia. Concurrently, the importance of ASEAN Economics Community (AEC) sustainable development for ASEAN has been highlighted throughout the region. To respond to this opportunity and experience in entrepreneurship and governance, it would be advantages to forge ahead in understanding the current public policies, local economic and people who are living in the ASEAN communities including their visions, aspiration, their needs, their culture and their outreach.

Particularly in pursue of sustainable economic development in the region for reducing social disparity while creating social equity and harmony for living together in the region.. Understanding this new practice may be well advised to apply the principle of social entrepreneurships in AEC ensuring projects have a better change of benefiting the people and economy in the region.

As the leaders of ASEAN countries have officially announced, in 2015 the ASEAN economic community (AEC) is become one community under its motto: "One Vision, One identity, One Community". The Association of Southeast Asian Nations, aiming to be community of stable, prosperous, and highly competitive 
region with equitable economic development, reduced poverty and socio-economic disparities (College of Management, 2012). However, the question is how AEC's leaders should develop sustain economic in the region remained to be answered. Part of the reasons is because the members of the 10 countries of AEC remained great differences in relation to social, economic, education and environmental issues in the region.

The Asian Development Bank (ADB, 2012) recently reported that "developing Asia will largely maintain its growth momentum in the next couple of years despite weak global demand. From moderate $7.2 \%$ in 2011 , growth in the region will ease $6.9 \%$ in 2012 before picking up to $7.3 \%$ in 2013". In Southeast Asia alone would grow from 5.2\% in 2012 to $5.7 \%$ in 2013 . However, the ADB reported that despite the growth of economic in the region, the region is facing the greater disparity in between the 'haves' and 'have nots'. This reflects a number of studies, for example, the United Nations Country Team in Thailand $(2010 ; 2007 ; 2011)$ which repeatedly indicated that the development of economic in Thailand over the past ten years have not everyone been benefited. The disparity between the haves and have-nots became wider, the top fifth of the population earned $55.2 \%$ of the total income, while the bottom fifth earned only $4.3 \%$ of total income.

Disparity between the haves and have-nots also happen in Indonesia . Central Bureau of Statistics Indonesia reported that in March 2014 , the number of poor people in Indonesia reached 28.28 million people or approximately $11.25 \%$ of total population in Indonesia. The number of poor people that live in urban areas reach 10.51 million $(8.34 \%)$, while, as much as 17.77 million poor people live in rural areas (14.17\%). These data demonstrate the high level of poverty population in Indonesia.

This research aims to examine and analyze social entrepreneurship in AEC. The main purpose of the research is to assess social entrepreneurship that has been developed in the region and to examine how the term is used and shaping current local economic. Some of research questions to be answered in this research are: 1). How is SE evolved in the region?; 2). What are the internal and external factors that drive the raise of SE in the region?; and 3). How does SE benefit for local people and poverty reduction?.

\section{Literature Review}

The new social movement for socially practice innovation is known as "Social Entrepreneurship" (SE). In fact, the terms social entrepreneur and social entrepreneurship are not new but have been appeared in the literature on social change since the 1960s and 1970s (Krypa, 2014). However, the term social entrepreneurship, for Asia, is new and in fact they were not used until to economic crisis in 1997. Since then the term is used and often referred to the rapidly growing number of organizations that have created models for efficiently catering to basic human needs that existing markets and institutions have failed to satisfy. Social entrepreneurship combines the resourcefulness of traditional entrepreneurship with a mission to change society.

The word 'social' is involved cultural driven and value practices in a society. A person enters to a company does so because of needs. These needs generally include at least three major needs which include economical, social, spiritual and intellectual needs. According to Martin \& Osberg (2007), social entrepreneurship consists of three components as follows: (1) Identifying a stable but inherently unjust equilibrium that causes the exclusion, marginalization, or suffering of a segment of humanity that lacks the financial means or political clout to achieve any trans- formative benefit on its own; (2) Identifying an opportunity in this unjust equilibrium, developing a social value proposition, and bringing to bear challenging the stable state's hegemony; and (3) Forging a new, stable equilibrium that releases trapped potential or alleviates the suffering of the targeted group, through imitation and creation of a stable ecosystem around the new equilibrium.

Social Entrepreneurship (SE), is created for recognition of a social problem and the usages of entrepreneurial principles to organize, create and manage a social venture to achieve a desired social change (The Free Encyclopedia Wikipedia, 2012). The focus of SE is not performance for profit returning to stockholders but the performance for profit returning to society aiming to further broaden social, cultural, and environmental goals. SE led by social values. Other words, making choices are based on value judgment which is known as value rationality (Flyvbjerg, 1998, 2001). This indicates that SE is socially inclusive while seeking for profits maximization. This is well associated with the study of Flyvbrgy (2001) indicated that social inclusive is vital for any sustainable development of economic. 
Social entrepreneurships is real practice of community based economic foundation. It grounded from the grassroots of people in society where are values based practices carried by community in society (Wasi Prawase, 2012). It is where unreasonable people found (Elkington \& Hartigan, 2008). Social entrepreneurship may leads to significant changes in the social, political, and economic contexts for poor and marginalized groups (Alvord, Brown \& Letts, 2004).

Social Entrepreneurship is social invention practices. It takes social aspects as based practices. As discussed, is created for recognition of a social problem and the uses of entrepreneurial principles to organize, create and manage a social venture to achieve a desired social change. It led by social values. Other words, making choices are based on value judgment which is known as value rationality (Flyvbjerg, 1998, 2001; Alvord, Brown \& Letts, 2004). To explain such social inclusive while seeking for profits maximization could not be done through the lens of globalization but through the lens of 'localization'.

It is Social Entrepreneurship strategy that explains the validity of SE and the way SE should be develop in 'AEC Society' or 'Global Society' (Figure below). It explains the development of organizations through the lens of Social aspect measurement (value rationality) of localization in Social Science practices not Social prediction aspect (prediction rationality) of globalization in predictive social science practices. A manager goes to local community. He or she starts business as community based business practices where are tradition, culture and social values always involved.

Increased social problems and many efforts attempted by various parties have made the topic of social entrepreneurship to be more widely discussed. In the literatures a lot of definitions of social entrepreneurship have been found with different emphasis, but there is no agreement on what is meant by social entrepreneurship.

Konda et al (2015) give the definition of social entrepreneurship as a process, the logic of action, which may occur in the different organizational context: charitable organizations, commercial organizations, government organizations, community organizations, or through a new venture. It is characterized by a set of principles that are usually included in the scope of: focus on value creation, focus on innovation, not on the status quo, focus on sustainable solutions of the organization, and focus on the empowerment of participants in the value chain. The essence of social entrepreneurship is simultaneous action to detect and identify social problems, as well as using entrepreneurial principles to achieve positive social change. In fact, social entrepreneurship is social innovation, because social enterprise shows how successful combination between business and social issues and the environment can be achieved.

Yunus (2009) argues that there are new and exciting opportunities to implement social enterprises, and the market is becoming increasingly attractive and competitive. Rather than focusing on generating profits, social enterprises have a good purpose, in this way they act as a factor of change. They provide products, services, customers, markets, inflows and outflows. However, the guideline that underlies them is social utility. Yunus provides an alternative - the enterprise is geared to maximize profits, but is managed by the poor.

Meanwhile, Kostetska, I. and Berezyak, I. (2014) view that social entrepreneurship is an innovative form of business, which has successfully managed to combine social objectives and commercial practice. Social entrepreneurship has emerged as a response to chronic social problems such as unemployment, poverty, fragmentation of society, and others. Social entrepreneurship works where the government can not work (due to lack of funds), and the business is not going well (due to low profitability). Private funds and international public are devoted to the development and maintenance of social entrepreneurship. Schwab Foundation for Social Entrepreneurship (Switzerland), Skoll Foundation (USA) and Ashoka Foundation (India) define social entrepreneurs as an innovative business activity for the society progress and the restoration of social justice (Spreckley, 2011). From the various definitions that exist, there are two important aspects to be emphasized in social entrepreneurship those are a social mission on one hand and business mission on the other hand.

\section{Research Method}

In examining the documentations, views and experiences of Social entrepreneurs in relation to job creation and economic community poverty reduction in the region, this research is conceptualized as an exploratory study. 
The target population of this research involves SE in Indonesia and Thailand. The study design was a multiple case study, which provides a comparative analysis of 5 cases of SE in each country. The selection of the cases is based on three criterias: (1) they are SE; (2) they are influenced by the public policy in the country; 3 ) all of the SEs have been established in the last five years.

The data were collected using in-depth interviews which were guided by sets of questions concerning how the leaders perceive or feel committed to SE practices in the day to day operations. All interviews will be taped and if any questions needed to be clarified, this will be done by way of Skype or telephone calls back to participants to ensure that comments of groups are accurately recorded and interpreted.

\section{Finding and Discussion}

\subsection{Overview of the initiator and the SE activities to be studied}

The results of this study were based on interviews and observations of 10 social entrepreneurs consisting of six social entrepreneurs in Indonesia and six social entrepreneurs in Thailand. The criteria for choosing the informants were based on local recognition of the achievements derived by the informants, some of which was indicated by the acquisition of award or other form of appreciation.

Among the actors of social enterprise companies who were chosen as informants, the earliest established the enterprise in 2003, most of the founders of the social entrepreneurship field were male (4 of 5) employers, had formal education varied from primary school up to Bachelor. The type of business developed had relevance to the social problems in the community such as the problem of education (alternative school Qaryah Thayyibah), poverty alleviation due to crop failure caused by rat (Owl breeding Tyto Alba), the issue of waste and environment (the utilization of water hyacinth and natural batik dye), and the empowerment of women and the development of local potential for the well-being of local communities (tourist village). One interesting thing from a general overview of the social entrepreneurship actors was that almost all players had an idea for SE activities from social problems around them, in the area where they live day to day.

For social entrepreneurs in Thailand, the founders were mostly missionaries. So it can be understood if the movement of social entrepreneurship in Thailand has been started a long time ago. For example Lanna Café that has been started since 1990, when missionaries performed many services in Thailand. Based on this fact it can be seen that the types of social enterprise developed in Thailand were developed based on social problems encountered, especially for marginalized groups, such as refugees, alienated tribes in the remote area, poverty and equal rights issues.

Furthermore, the initiators and founders of social entrepreneurship activities in Thailand had a quite high formal educational background, and the majority had bachelor degree. One of the key informants from Thailand, Mr. Miang, who initiated the establishment a tourist village of "Mae kampong" although only had formal education of senior high school that he earned through distance learning program, but he had vision and insights no less that those who had higher formal education. This time after the concept of "Tourist Village" he built made a positive impact and is widely known, Mr. Miang is often invited to various universities and institutions to express His views and experiences in the field of social entrepreneurship. He has obtained a number of awards from the government and various other parties of His work in the field of social entrepreneurship.

\subsection{Background of the Idea of Social Enterprises}

Almost all background that became the motivation of the initiators to raise the idea of SE came from the social problems and issues developed in the region around. The social problems were generally related to poverty, education, health, all of which were felt directly by the SE initiators. In the case of Mr.Baharuddin, his reason to initiate SE was due to the problems of poverty and the weak position of the bargaining power of the farmers (small people) with the government as policy maker.

Background associated with poverty issues was expressed by almost all informants who were investigated for the case in Indonesia. For example Mr. Sutejo who is known as SE figure for his initiation in owl Tyto alba. He also expressed that the idea arose because could not bear to see the villagers of Tlogoweru village in which he became a village head, lived in poverty because they did not enjoy the harvest for many years due to pest rodents. 
The background of the emergence of other SE idea that was further uncovered from this study is the desire to maintain balance and environmental sustainability. It is implied clearly from the interview to Mrs. Chomsah, who developed clusters of water hyacinth, Mrs. Srini who developed female farmer groups for the cultivation of healthy organic plantation, and Mr. Sarwidi, batik craftsman who produced batik just by using natural dyes from nature. Then Mr. Yos also founded Yos Traditional Centre to keep and conserve the traditional local wisdom culture. Mr. Yos also found and helped the development of tourist village with the concept of eco-tourism.

The similar background and motivation were found in the emergence of SE in Thailand. Social problems in communities attracted the attention of the SE initiators in Thailand were also revolved around the issued of poverty, low quality of life and also the problem of poor education. WEAVE fair trade Social Enterprise Organization, which was founded in 2012 in Chiang Mai Thailand, because of the condition of the refugees, especially women who were accommodated in Camp at the border area of Thailand and Burma for almost 30 years, they were isolated and consisted of about 120,000 people.

Other Social Enterprises in Thailand that were interviewed in the study were Lanna Café, Tobee bays, Tourist Village Mae khampung, Thai Tribal Craft Fair Trade.Co. Ltd, and Akha Ama Coffee, all of which were established with a mission to help alleviate poverty in the community or specific communities. Beside triggered by the poverty problem, environmental issue also received attention from SE in Thailand, such as the initiator of the Tourist Village Mae khampong which implemented eco tourism concept that considering the balance with nature.

The difference of the quite striking background of the emergence of SE idea between Thailand and Indonesia was the founders of SE in Thailand who were mostly missionaries, social workers, and church activists. It is thought to have implications on the broader scope of social issues (national) compared to SE in Indonesia whith regional or local scope. The target group of SE in Thailand could range from refugees to groups of hill tribes. In other hand, the target groups of SE in Indonesia in the study were more focused at the village level where the SE initiators come from. As a consequence, the social issues that were managed by SE in Thailand were also more complex than SE in Indonesia.

\subsection{The Benefits of Social Entreprises for the Community}

The purpose of Social Enterprise is to address the social problems in the community as the background of SE establishment. Even in macro level, the role of SE is supposed to have an impact on poverty reduction, or in other words SE can improve the welfare of the society. In this study, based on the observations and interviews with the informants, we obtained a number of positive impacts from SE.

One benefit of the SE movement commonly found was that SE could provide employment opportunities through the emergence of new job opportunities being offered. This benefit included the member of Water Hyacinth Handicraft Cluster "Klinting" which recognized to get a second job to make handicrafts from water hyacinth to fill their spare time productively. Beside the benefits of opening new employment opportunities, SE also provided other benefits which could increase the productivity and welfare of the community. As a result, the quality of their lives became better

For the case in Thailand, SE also showed benefits that were not much different from the case of SE in Indonesia. Open employment opportunities, increase income and improve the quality of life of the target group were the mostly recalled benefits. But some SE such as Weave and Thai Tribal also created other benefits, namely preserved weave local cultures which is the specific cultural value of local wisdom of certain tribes. In addition, the two SEs also educated the target group to standardize products and conduct business in a fair manner to introduce the principles of Fair Trade. Moreover the tourist village Maekhampong introduced the concept of management based on eco-tourism sites, and it hoped to give benefit of eco-friendly tourism management example which is closer to nature, so as to lead a sustainable effort.

\subsection{Discussion}

The theory of localization (Covey, 1990) states that a social entrepreneur is emerged from local people who understand the social problems faced by a social group in the community and want to contribute to find solutions for the community. This occurs in social entrepreneurship in Indonesia and Thailand. In Indonesia, all respondents of initiators of social enterprises were local Indonesian people even the majority came from the 
place where the problems arose. Meanwhile in Thailand, the founders of social entrepreneurship were local people and missionaries who came from foreign countries. Local people such as Lee and Miang were called to solve the problem of poverty in the communities where they were born and grown. Meanwhile the missionaries came to Thailand because of their high commitment to humanitarian issues including addressing the issue of poverty of the refugees group that became a concern by international agencies such as UNHCR.

The factors that determine the emergence of social entrepreneurship can be divided into two groups: internal and external factors. Internal factor is individual character, education and training, experience, parenting pattern, and family support. Individual character is formed from all walks of life experienced by individuals such as poverty experienced during childhood that makes an individual has an obsession to be free from poverty. Sensitivity owned will make someone not just want to be free of trouble alone but also for the community in which he lives and grows. Some social entrepreneurs feel guilty when they have succeeded in changing their social life while many other people from the same or different community still entangled with difficulties. Background and parenting pattern that teach positive values also form a struggle power of someone, not easily discouraged, and willingness to share. Education and experience also contribute to the ability and the courage to start a social enterprise.

The core issues that drove the emergence of social enterprise in Indonesia and Thailand were actually the same, although there were different levels of complexity. In Indonesia, the SE initiators were not generally formalized the institutional efforts and the worked by focusing on addressing the problems faced by the community. This may be due to limited funding, which generally rely on the financial support of the SE initiators or the absence of power owned by the initiators. In the development of tourist village, SE played role as a motivator, coordinator and facilitator to be able to access the sources of funding available in the government. In Thailand, SE activities were originally done informally but then social enterprises were legalized into a formal company. In Thailand, the approach used to address the problems faced by the society was more integrated. For example, to increase revenue, they also targeted the improvement of health and education. Again, the availability of funds and the authority possessed by the entrepreneurs will determine. Legality is probably encouraged the SE initiators in Thailand to apply the principles of business management more professionally.

Compared to Indonesia, social problems faced by social enterprises in Thailand were complex and heavy although they came to one goal, namely an increase in target public welfare (economic, education, health). From the social enterprise case in Thailand, the characteristics of the social entrepreneur can be grouped into 3 major groups namely mindset, managerial and skill. With regard to the mindset, social entrepreneurs are demanded to be visionary, innovator, being a change agent. They are required to have managerial skills in business management. Meanwhile with regard to skill, it includes communication skills such as the ability to speak English, the ability to establish relationships (networking skill), as well as technical skill as the ability to understand a quality product and a good process.

\section{Conclusion}

The study results on social entrepreneurship in Indonesia and in Thailand found that social entrepreneurship movement occurred a lot in Indonesia and Thailand. However, the understanding and coverage of social entrepreneurship was still very diverse in the community. Ideally, social entrepreneurship arises because of the social problems in the community, and it is expected that the problems can be managed professionally and in business oriented manner through social enterprise, so that the social problems can be addressed and have sustainable impact. Based on the coverage and understanding of SE, it appears that SE in Thailand was closer to the ideal definition of SE, in contrast with SE in Indonesia which was closer on handling social issues, but the long-term sustainability was still in question because it was not supported by an integrated business concept.

Other findings from this study indicated that the majority of initiators of SE in Indonesia came from the local community so that the scope of SE was more regional. In contrast with Thailand where most of the initiators of SE were missionaries and social workers, so that social issues were addressed in broader national scope. The study results also showed that the background of the social issues raised as the basis for the mission of the SE were majority revolved around the problems of poverty, poor health and education. Those were 
applied to the SE in Indonesia and Thailand. More specifically, the environmental and cultural preservation issues were also the focus of the issues to be managed by SE in the two countries.

Related to the benefits or positive impacts of SE, SE in both Indonesia and Thailand seems to be capable of providing employment opportunities or in other words it may reduce unemployment, especially to fill the leisure time. Another benefit is a better increase in income and quality of life of the group target. Furthermore SE can also give benefits on living environmental issues.

\section{References}

[1] Alvord, S.H., Brown, D.L., \& Letts, C.W. (2004). Social Entrepreurships and Societal Transformation: An Exploratory Study, Journal of Applied Behavioral Science, 40, 260-282.

https://doi.org/10.1177/0021886304266847

[2] Asian Development Bank. (2012). Poverty Reduction: Promoting Inclusive Pro-Poor Growth. Retrieved from http://www.adb.org/themes/poverty/main

[3] Boschee, Jerr \& McClurg, Jim. (2003). Toward a Better Understanding of Social Entrepreurships. download from http;//www.selliance.org/better_understanding.pdf.15 Mar 2014

[4] Elkington, J., \& Hartigan, P. (2008). The Power of Unreasonable People: How Social Entrepreneurs Create Markets that change the world: Harvad Business School Press.

[5] Flyvbjerg, B. (2001). Making Social Science Matter: Why social inquiry fails and how it can succeed again (S. Sampson, Trans.). Cambridge, United Kingdom: Cambridge University Press.

https://doi.org/10.1017/CBO9780511810503

[6] Flyvbjerg, B. (2004). Five misunderstandings about case-study research. In C. Seale, G. Gobo, J. F. Gubrium \& S. David (Eds.), Qualitative Research Practice (pp. pp.420-434). London and Thousand Oaks, CA: Sage.

https://doi.org/10.4135/9781848608191.d33

[7] Friedman, M. (1999). The Social Responsibility of Business is to Increase its Profits. In P. H. Werhane \& T. Donaldson (Eds.), Ethical Issues in Business (six Edition ed., pp. 154-159): Prentice-Hall, Inc.

[8] Kotler, P., \& Lee, N. R. (2009). Up and Out of Poverty: The Social Marketing Solution New Jersey: Pearson Education, Inc.

[9] Prawase, W. (2006). Potential of Business and Financial sector for solution of Social Crisis in the Soociety. Paper presented at the Business and Corporate Social Responsibility: Concept and Practices

[10] Prawase, W. (2012). Strategic Local Community: National strategy for sustainable development. Bangkok: Thai Health Fund.

[11] The Association of Southeast Asian Nations. (2012). ASEAN Motto. Retrieved from http://www.asean.org

[12] The Free Encyclopedia Wikipedia. (Ed.) (2012) Wikipedia: The Free Encyclopedia. The Wikimedia Foundation, Inc.

[13] United Nations Country Team in Thailand. (2005). Thailand Common Country Assessment Retrieved from http://www.undp.org/asia/country_programme/CCA/CCA-Thailand2005.pdf

[14] United Nations Country Team in Thailand. (2010). The Real Wealth of Nations: Pathways to Human Development. 20th Anniversary Edition. Retrieved from http://www.undp.or.th/documents/HDR_2010_EN.pdf

[15] United Nations Development Program. (2007). Thailand Human Development Report.

[16] United Nations Thailand. (2011). Thailand Infor: Overview. Retrieved from http://www.un.or.th/thailand/index.html 